\title{
Rapid Recovery from Critical COVID-19 Respiratory Failure after treatment with VIP
}

\section{J. Georges Youssef}

Houston Methodist Hospital

Jonathan Javitt ( $\nabla_{\text {jjavitt@jhu.edu ) }}$

Johns Hopkins University https://orcid.org/0000-0003-2371-1609

Mukhtar Al-Saadi

Houston Methodist Hospital

Faisal Zahiruddin

Houston Methodist Hospital

Sarah Beshay

Houston Methodist Hospital

Mohammad Z. Bittar

Houston Methodist Hospital

\section{Biological Sciences - Article}

Keywords: Vasoactive Intestinal Peptide, VIP, SARS-CoV-2, COVID-19, Acute Respiratory Distress Syndrome, ARDS, Acute Lung Injury, ALI, surfactant, Alveolar Type II

Posted Date: September 21st, 2020

DOI: https://doi.org/10.21203/rs.3.rs-68707/v1

License: (c) (i) This work is licensed under a Creative Commons Attribution 4.0 International License.

Read Full License 


\section{Rapid Recovery from Critical COVID-19 Respiratory Failure after treatment with VIP}

J. Georges Youssef, MD ${ }^{1,2}$

Jonathan C. Javitt, MD, MPH ${ }^{3,4}$

Mukhtar Al-Saadi, MD, EdD ${ }^{2}$

Faisal Zahiruddin, DO ${ }^{2}$

Sarah Beshay, MD ${ }^{2}$

Mohammad Z. Bittar, MD ${ }^{2}$

Author Affiliations:

1. Houston Methodist Pulmonary Transplant Center, Houston Methodist Research Institute, Houston Methodist Hospital, Houston, Texas, USA

2. Department of Academic Pulmonology, Houston Methodist Hospital, Houston, Texas

3. NeuroRx, Inc. Wilmington, DE

4. Adjunct Professor, Johns Hopkins University School of Medicine, Baltimore, MD

\section{Keywords}

Vasoactive Intestinal Peptide, VIP, SARS-CoV-2, COVID-19, Acute Respiratory Distress Syndrome, ARDS, Acute Lung Injury, ALI, surfactant, Alveolar Type II

Word Count: 2962

Correspondence to: jjavitt@jhu.edu

Funding: Research support was provided by the Cavendish Impact Foundation and Princeton Alumni Angels. Clinical trial funding was provided by Relief Therapeutics Holdings, AG, Geneva and NeuroRx, Inc.

Disclosure: Author JCJ is employed by NeuroRx, Inc., a pharmaceutical company that is currently conducting clinical trials of RLF-100 in patients with COVID-19 and is Vice Chairman Elect of Relief Therapeutics. 


\begin{abstract}
Background: Vasoactive Intestinal Peptide (VIP) blocks replication of the SARS-CoV-2 virus, inhibits cytokine synthesis, prevents cytopathy, and upregulates surfactant production in human pulmonary cells. RLF-100 ${ }^{\mathrm{TM}}$ (aviptadil), is currently in phase 2/3 trials with FDA Fast Track designation for treating Critical COVID-19 with Respiratory Failure.
\end{abstract}

Methods: Case series of 21 consecutive with Critical COVID-19 and multiple co-morbidities, treated with intravenous aviptadil (synthetic VIP). Sixteen patients were treated with ventilation alone and five with extracorporeal membrane oxygenation (ECMO).

Results: So far, 19 of 21 patients have survived. Improved radiographic appearance was seen in both lungs of 17 patients and in one lung of 2 patients. A mean 2.5-fold increase in $\mathrm{PaO} 2$ :FiO2 ratio was seen $(\mathrm{P}<0.0001)$ with complete remission from respiratory failure in 9 patients and ongoing improvement in 10. Seven patients were discharged from the hospital, 7 sent to intermediate care, and 5 remain in the ICU. Four of 5 patients on ECMO have been decannulated, and thus far three have been discharged. A 75\% (95\% CI $\pm 3 \%$ : P<.001) reduction in IL-6 was seen with corresponding decrease in $\mathrm{C}$-reactive protein. A median 3 point reduction (mean 2.7; $\mathrm{P}<0.001$ ) in the WHO Ordinal Scale was observed $(\mathrm{P}<.001)$.

Comment: The short term outcome in these 21 patients represent a dramatic response in patients whose comorbidities precluded their randomization in all other trials of COVID therapeutics and who were previously treated with remdesivir, tocilizumab, or convalescent plasma. Improvement in radiographic appearance, oxygenation requirement, and inflammatory markers is consistent with in vitro evidence of direct anti-viral effect

\title{
Background
}

50 years ago, Nature published the first report of a novel peptide discovered in the gut of patients with atypical presentation of diarrhea and flushing. ${ }^{1}$ Said and Mutt named it Vasoactive Intestinal Peptide (VIP). Over the subsequent 50 years, VIP was discovered to have remarkable properties in protecting the lung from all manner of injuries and we now understand that its site of action is the Alveolar Type II cell.

Vasoactive Intestinal Peptide (VIP) is shown to block replication of the SARS-CoV-2 virus in human pulmonary epithelial cells and monocytes, while also demonstrating clinical improvement on radiographic and laboratory parameters. ${ }^{2}$ In addition to its antiviral effect, VIP protects the Alveolar Type II (ATII) cell by upregulating surfactant production, blocking apoptosis, and blocking cytokine effects. In vitro evidence suggests that human monocytes treated with VIP secrete soluble agents that further protect ATII cells via a "bystander effect."

Aviptadil, a synthetic form of Vasoactive Intestinal Peptide (VIP) has been granted Fast Track Designation and is currently in phase 2/3 placebo-controlled trials (NCT04311697). FDA has granted Emergency Use IND and Expanded Access Protocol approval NCT04453839 for the use of RLF-100 in patients whose comorbidities render them ineligible for inclusion in the ongoing pivotal trial. These comorbidities, predictive of poor outcomes in COVID19, were deemed to be sufficiently rare that enrollment could not adequately be balanced within the structure of the randomized trial. That is particularly true of patients whose pulmonary function has deteriorated to the point of requiring Extracorporeal Membrane Oxygenation (ECMO) to sustain life.

VIP has been shown to protect the lung against a broad array of caustic, immune, and infectious injuries $3,4,5,6$ through its binding to the $\mathrm{VPAC}_{1}$ receptor of the Alveolar Type II cell. This is the same pulmonary cell to which the SARS$\mathrm{CoV}-2$ virus binds via the ACE2 receptor ${ }^{7}$. VIP by intravenous administration has previously demonstrated effectiveness in treating ARDS related to sepsis. ${ }^{8}$ Promising results have been shown with inhaled administration in treating sarcoid ${ }^{9}$, and pulmonary hypertension. ${ }^{10,11}$

\section{Patients and Methods}

Human subjects' protection was overseen by Advarra IRB, the Institutional Review Board (IRB) of the Houston Methodist Hospital, and by an independent Data Monitoring Committee. Twenty one patients with PCR-proven COVID-19 and respiratory failure were screened for NCT04311697 and deemed ineligible on the basis of exclusionary comorbidity (see clinicaltrials.gov). On that basis, they were offered treatment with aviptadil, initially under FDA Emergency Use IND, which FDA subsequently converted to an intermediate population size Expanded 
Access Protocol (EAP), NCT04453839. Under Emergency Use IND, FDA was contacted prior to the treatment of each patient and approved the use of intravenous RLF-100. Under EAP, treatment was administered per FDAapproved protocol. Investigational product was donated for expanded access use by NeuroRx, Inc. (Wilmington, DE).

The first 21 consecutive patients enrolled as above are described in this report. Patients had a critical level of respiratory distress $\left(\mathrm{PaO}_{2}: \mathrm{FiO}_{2}\right.$ ratio $\left.=91.6\right)$ at study entry with radiographic evidence of severe COVID-19 pneumonitis. The median WHO ordinal scale at entry was 9, (mean 7.6), denoting patients in the highest risk category for mortality. Sixteen were treated with mechanical ventilation at time of enrollment and 5 with mechanical ventilation plus ECMO. Each of the patients enrolled in this emergency use program was experiencing clinical deterioration at the time of enrollment despite receiving maximal intensive care. The median age of patients was 61 (Interquartile range [IQR] = 25 years) and there were 10 male and 11 female patients (see supplemental online material Table 1). Following informed consent each patient received three 12-hour intravenous infusions of aviptadil at graduating doses of 50, 100, and 150 $\mathrm{pmol} / \mathrm{kg} / \mathrm{hr}$. One patient (Patient 10) received only the first two infusions because he developed hemorrhagic shock caused by a chest tube inserted to treat a spontaneous pneumothorax while on ECMO. Patients received background treatment with remdesivir $(n=6)$, tocilizumab $(n=18)$, and convalescent plasma $(\mathrm{n}=2)$ as available and per the treating physician's discretion. All patients were treated with systemic steroids and anticoagulation.

Hypothesis testing was by paired t-test.

\section{Clinical Results}

Median patient follow-up time is 21 days. So far, 19 of 21 patients have survived. One death was due to COVID-related multisystem organ failure and the other (on ECMO) to an underlying and unrelated encephalopathy, which led the family to withdraw life support. Four of the five patients on ECMO were successfully decannulated.

Twenty of 21 patients demonstrated substantial improvement in blood oxygenation (Fig 1). The improvement in patients on ECMO was similar to that seen in patients treated with conventional mechanical ventilation. Available data from blood gases showed clear increases in $\mathrm{PaO} 2: \mathrm{FiO} 2$ ratio after the $2^{\text {nd }}$ dose (Median increase $=92.5, \mathrm{IQR}=$ 74 ) and at 24 hours after the $3^{\text {rd }}$ dose (Median increase over baseline $84.5, \mathrm{IQR}=110$ ). No patient showed deterioration of oxygenation below baseline during subsequent measurements.

Radiographic evidence (Fig 2) on all patients is included in the online supplementary material. Full or partial resolution of the "ground glass" parenchymal changes associated with COVID-19 pneumonitis in 17 patients, unilateral improvement was seen in 2 patients and no Effect of VIP on Blood Oxygenation improvement/worsening seen in 2 patients on radiologic examination.

Quantitative analysis of radiographic changes will be the subject of a future report. 
A laboratory panel of inflammatory markers, including $\mathrm{LDH}$, troponin, C-reactive protein, ferritin, D-Dimer, and interleukin 6 was obtained prior to and post treatment with aviptadil (figure 3). In all patients, improvement can be seen on each of the inflammatory markers. The largest average percent decrease was seen in C-reactive protein $(76 \% \pm 3 \%)$ and interleukin $6(75 \% \pm 3 \%)$. No patient demonstrated an increase in any of the inflammatory markers.

\section{Hospital course and adverse events.}

The time to resolution of respiratory failure ranged from 3 - 20 days (mean 10.5) and time to ICU discharge ranged from 1 - 21 days (mean 8.1) in the 10 of 21 patients so far discharged from intensive care (Table 2). Clinical narratives are included in the online supplementary material. There were various complications in hospital courses following completion of the aviptadil regimen as would be expected in patients with this degree of comorbidity. For instance, patient 2 was scheduled for discharge to home 3 days following completion of treatment but fell in the hospital and suffered a retroperitoneal bleed which led to a subsequent 10 day course of inpatient care. Patient 4 , who was about to be treated with extracorporeal membrane oxygenation (ECMO) successfully demonstrated improvement in respiratory distress but developed line sepsis with confirmed $S$. Epidermidis, which has led to chronic respiratory distress and continued ventilation. Patient 4's hospital course was complicated by an apical pneumothorax attributed to prone positioning that occurred 24 hours after completing Aviptadil therapy. The pneumothorax spontaneously resolved after discontinuation of prone positioning and no chest tube was required. Vasopressors were administered for continued acidosis and hypotension and were subsequently weaned. The patient was started on inhaled nitric oxide and CRRT. The patient had slow clinical and radiologic improvement but remains in the ICU requiring ventilatory support.

No drug-related Serious Adverse Events (SAEs) including mortality were recorded.

Only one patient developed a drug-related (nonserious) adverse event. Hypotension was seen in two patients that was successfully managed with pressors and did not require cessation of infusion.

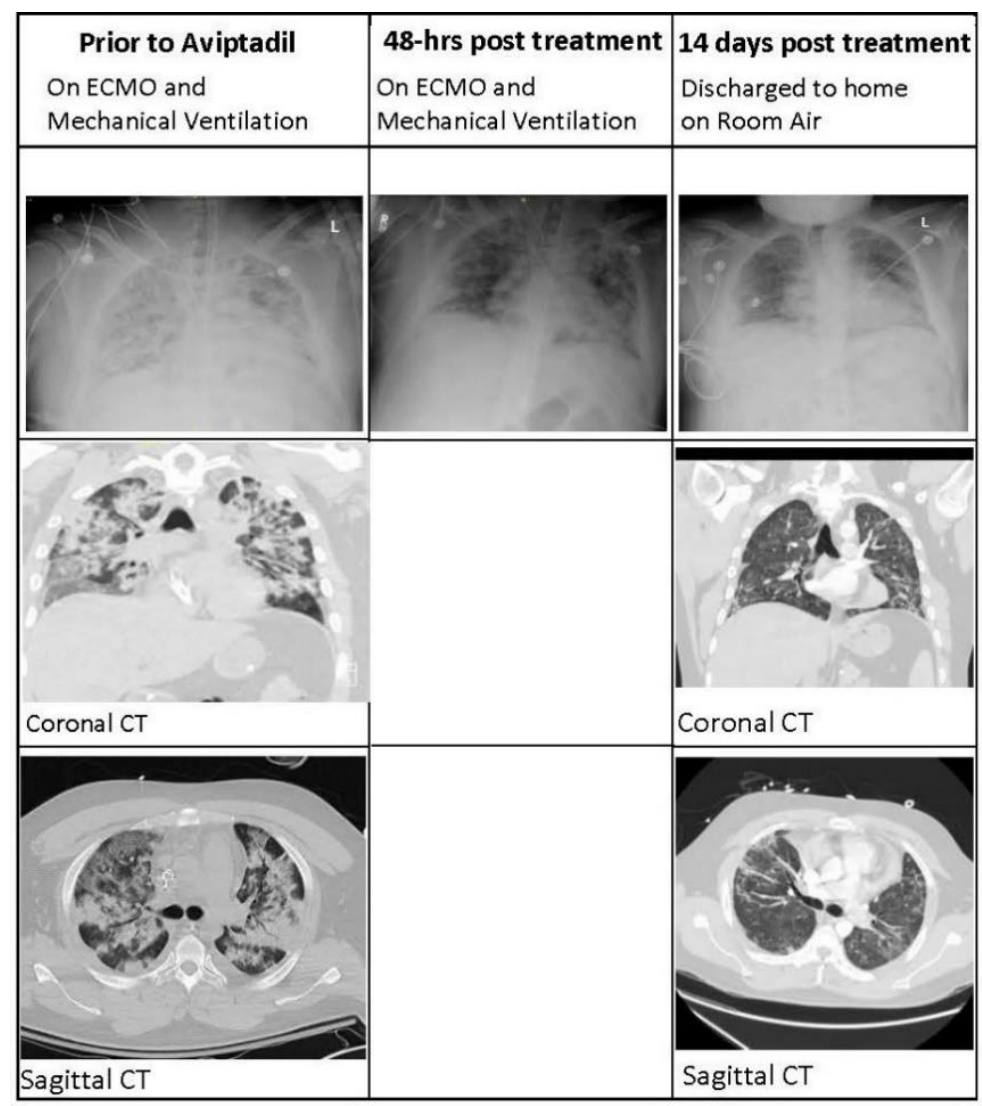

Figure 2: Chest x-ray and $\mathrm{CT}$ imaging of a patient initially treated while on mechanical ventilation and extracorporeal membrane oxygenation for Critical COVID-19 with respiratory failure (see supplemental online material for radiographic documentation of all patients).

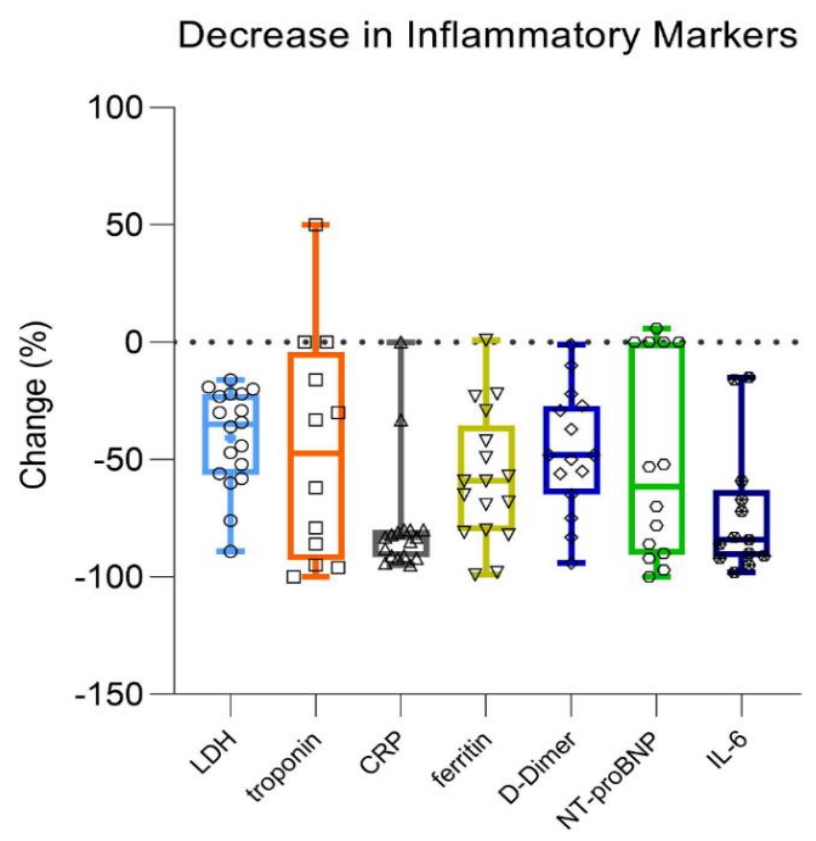

Figure 3: Decrease in inflammatory markers as a percent change from pretreatment value. The decrease is both clinically and statistically significant $(\mathbb{P}<.001)$ 
Diarrhea was seen in 4 patients, consistent with the known metabolic effects of VIP. Clinical experience shows that diarrhea is minimized when patients are pretreated with immodium and albumin. Nevertheless, ICU staff should be prepared to use a fecal management system and monitor fluid/electrolyte loss when treating with high doses of intravenous VIP.

Clinically and statistically significant improvement was seen on the WHO Ordinal Scale (Fig 4), where zero represents discharge to home with no need for further therapy and 10 represents death can be seen in both ventilated and ECMO-treated patients. The median improvement was 3 points (mean 2.7 points; $p<0.001$ ).

\section{Discussion}

The 21 patients in this report were at the highest risk for mortality on respiratory parameters had serious comorbidities that made them ineligible for participation in the ongoing FDA phase $2 / 3$ pivotal study of RLF-100 (aviptadil) in the treatment of COVID-19 respiratory failure. Remarkably, 10 have been discharged on room air or pre-admission levels of oxygen therapy. Only one patient died of COVID-related disease and life support was withdrawn by the family in another because of an underlying encephalopathy. Twenty of 21 patients demonstrated rapid clinical improvement in blood oxygenation and 17 demonstrated accompanying changes in radiographic features. The substantial decrease in inflammatory markers seen in all patients, particularly in ferritin, D-Dimer, and IL6 which are increasingly associated with poor prognosis in COVID-19 suggests that the radiographic and oxygenation improvement seen in these patients may be tied to an etiologic effect of Aviptadil. The fact that 19 of 21 patients have, so far, survived is highly unexpected in COVID-19 patients with this degree of comorbidity and the fact that 11 of 21 have been discharged from ICU care with hope for successful discharge in 8 others is equally remarkable. Indeed, 4 of those currently remaining in ICU suffer primarily from respiratory muscle weakness and are awaiting tracheostomy so that they can be progressed to intermittent ventilation and moved to longterm acute care. One of three patients who remain in the ICU was scheduled for extubation when a pneumothorax developed that required additional ventilatory support, while another continues to suffer from non-COVID complications caused by a hemorrhage associated with chest tube insertion.

This is the second clinical report in which aviptadil has been associated with a remarkable degree of improvement in patients with Acute Respiratory Distress. In 2005, 8 patients with sepsis-related Acute Respiratory Distress Syndrome were treated with the same intravenous VIP protocol. ${ }^{12}$ All 8 patients demonstrated clinical improvement, 7 were discharged from intensive care and life support was terminated in the $8^{\text {th }}$ for neurologic, rather than pulmonary reasons. Although the case series was not reported until recently because of the retirement and subsequent demise of the senior author, the clinical care was managed and results recorded by one of our authorship (JGY). Similar clearing of pneumonitis with aviptadil (delivered by nebulizer) was recently reported in a patient with checkpoint inhibitor pneumonitis. ${ }^{13}$

Early COVID-19 lung injury is characterized by a remarkable degree of hypoxemia in the absence of overwhelming pneumonia, suggesting a primary injury to the pulmonary gas-exchange mechanism. Although named (or mis-named) for the gut where it was first isolated, 70\% of VIP is localized to the lung and binds primarily to Alveolar Type II cells (ATII) cells via VPAC $1 .{ }^{14}$ ATII cells comprise only $5 \%$ of the pulmonary epithelium but are critical to surfactant
P a g e | 5 
production and recycling as well as to the maintenance of type I epithelial cells. The SARS-CoV-2 virus specifically attacks ATII via their ACE2 surface receptors and does not enter the Type I pneumocyte. ${ }^{15}$ VIP preserves the function of lung allografts and may have been particularly beneficial in this patient who was suffering active graft rejection. ${ }^{16,17}$

Unlike synthetic anti-cytokines, such as anti-IL6 drugs, VIP is shown to have a specific role in preserving surfactant production in the lung. ${ }^{18,19,20,21}$ Accordingly, VIP and longer acting modifications of VIP have been proposed in the past as respiratory therapeutics ${ }^{22}$. Li demonstrated in rat lung explants that VIP increased the incorporation of methylcholine into phosphatidylcholine -- the major component of the pulmonary surfactants -- by enhancing the activity of the enzyme choline-phosphate cytidylyltransferase. ${ }^{16}$ VIP upregulates C-Fos protein expression in cultured type II alveolar cells, which is instrumental in promoting synthesis of pulmonary surfactant phospholipids ${ }^{17}$ and induces surfactant protein A expression.

\section{Conclusion:}

The significant clinical improvement seen in these 21 patients treated with intravenous RLF-100 ${ }^{\mathrm{TM}}$ (aviptadil), is consistent with the finding that VIP both blocks viral replication in pulmonary ATII cells and creates a "bystander effect" whereby nearby monocytes secrete soluble antiviral agents to further protect ATII cells, blocks cytokine storm, and improves oxygenation in a lung that is under attack by the SARS-CoV-2 virus. The rapidity and magnitude of clinical effect has not been reported to our knowledge in association with any other COVID-19 therapeutic agent, suggesting a highly specific role of VIP in combating the lethal effects of SARS-CoV-2 infection.

A phase 2/3 randomized prospective trial is underway, which will attempt to demonstrate that intravenous aviptadil improves recovery from respiratory failure, survival, oxygenation, and clinical course in patients with Critical COVID-19. The independent Data Monitoring Committee of that trial has conducted the first unblinded look at the study data and identified no safety signals. Moreover, the DMC has determined that the study is not futile in its objective to identify a statistically significant difference between aviptadil and placebo in remission from COVID-19 respiratory failure.

The patients reported here were excluded from enrolment in the ongoing phase $2 / 3$ clinical trial because of underlying comorbidity. Most notably, five of the patients included in this series were treated with ECMO, an end-stage treatment known for mortality of at least $31 \%$, with 53\% of patients still on ECMO after 3 weeks. ${ }^{23}$ Need for ECMO represents both an exclusion from enrolment and a treatment-failure event in the phase $2 / 3$ trial.

The clinical course of the patients in this study, with some having demonstrated rapid clinical recovery and discharge to home while others continue to improve more slowly, is striking for the consistency of improvement on radiographic changes, blood levels of inflammatory markers, and improvement in blood oxygenation. The radiographic improvement seen in these patients, is highly atypical for COVID-19 and suggests that aviptadil may be effective in treating COVID-19 and has substantial potential to demonstrate efficacy in adequately-controlled trials.

These results should be interpreted in light of the understanding that only a minority of those infected with SARSCoV-2 develop COVID-19. The finding that survival in those with COVID-19 respiratory failure is correlated with natural levels of VIP is particularly thought-provoking. ${ }^{1}$ If SARS-CoV-2 can be prevented from infecting and replicating in vulnerable nasopharyngeal and pulmonary cells that display ACE2 surface receptors, coronavirus is potentially a low-threat pathogen to humans, as it is to other mammalian species. Indeed, while non-human mammals can be infected with SARS-CoV-2, none seem to develop lethal COVID-19.

Our findings suggest that patients with earlier stage disease and an intact pulmonary epithelium may benefit from inhaled aviptadil in order to prevent progression to respiratory failure. FDA has granted an inhaled use IND and a phase 2/3 trial of inhaled aviptadil (NCT04360096) is about to commence. Aviptadil may have further value as a nasopharyngeal drug to prevent SARS-CoV-2 from successfully infecting nasopharyngeal cells and starting the pathogenic process of COVID-19. Moreover, aviptadil may have promise in treating a broad array of pulmonary inflammatory conditions.

Unlike expensive-to-produce monoclonal antibodies and difficult-to-scale convalescent plasma, VIP can ultimately be produced at a cost of pennies per dose, if moved from peptide synthesis to yeast fermentation, as is done for insulin. As such, it may represent a critical therapeutic for COVID-19 and possibly other viral infections for both the developed and the developing world. 
Acknowledgements: The authors wish to acknowledge Darrel Cleer, Beatrice Effron, and Marianne Younes of the Houston Methodist Hospital for clinical trials management, Matthew Javitt, MD for medical writing support, Gabriel Javitt BS for medical graphics, and Yves Sagot, PhD, for helping to conceptualize the study.

\section{References}

${ }^{1}$ Said SI, Mutt V. Potent peripheral and splanchnic vasodilator peptide from normal gut. Nature. 1970; 225: 863-864.

${ }^{2}$ Temerozo JR, Sacramenta Q, Fintelman-Rodriques N, et. al. The neuropeptides VIP and PACAP inhibit SARS-CoV-2 replication in monocytes and lung epithelial cells, decrease the production of proinflammatory cytokines, and VIP levels are associated with survival in severe Covid-19 patients doi: https://doi.org/10.1101/2020.07.25.220806

${ }^{3}$ Said SI. Vasoactive intestinal peptide in the lung. Ann NY Acad Sci 1988;527:450-464

${ }^{4}$ Said SI. VIP as a modulatory of lung inflammation and airway constriction Am Rev Respir Dis 1991;143:S22-S24.

${ }^{5}$ Said SI, Dickman KG. Pathways of inflammation and cell death in the lung: modulation by vasoactive intestinal peptide. Regul. Pept. 2000;93:21-29

${ }^{6}$ Javitt, J and Youssef, JG., VIP: A COVID-19 Therapeutic that Blocks Coronavirus Replication (August 9, 2020). Available at SSRN: https://ssrn.com/abstract=3670129

${ }^{7}$ Mason R. Pathogenesis of COVID-19 from a cell biologic perspective. Eur Respir J. April 9 Epub ahead of print. https://www.ncbi.nlm.nih.gov/pmc/articles/PMC7144II60/

${ }^{8}$ Said SI, Youssef JG, Youssef G, Javitt MJ and Javitt, Jonathan, Treatment of Sepsis-related Acute Respiratory Distress Syndrome with Vasoactive Intestinal Peptide (July 29, 2020). http://dx.doi.org/10.2139/ssrn.3662952.

${ }^{9}$ Prasse A, Zissel G, Lützen N, Schupp J, Schmiedlin R, Gonzalez-Rey E, Rensing-Ehl A, Bacher G, Cavalli V, Bevec D, Delgado M, Müller-Quernheim J. Inhaled vasoactive intestinal peptide exerts immunoregulatory effects in sarcoidosis. Am J Respir Crit Care Med. 2010;182:540-8

${ }^{10}$ Petkov V, Mosgoeller W, Ziesche R, Raderer M, Stiebellehner L, Vonbank K, Funk GC, Hamilton G, Novotny C, Burian B, Block $\mathrm{LH}$. Vasoactive intestinal peptide as a new drug for treatment of primary pulmonary hypertension. J. Clin. Invest 2003;111:1339-1346.

${ }^{11}$ Leuchte HH, Baezner C, Baumgartner RA, et. al. Inhalation of vasoactive intestinal peptide in pulmonary hypertension. Eur Respir J 2008;32:1289-1294.

12 Youssef, J.G.; Said, S.; Youssef, G.; Javitt, M.J.; Javitt, J.C. Treatment of Acute Respiratory Distress Syndrome with Vasoactive Intestinal Peptide. Preprints 2020, 2020070453 (doi: 10.20944/preprints202007.0453.v1).

${ }^{13}$ Frye BC, Meiss F, von Bubnoff D, Zissel G, Muller-Quernheim J. Vasoactive intestinal peptide in checkpoint inhibitor-induced pneumonitis. N Engl J Med 2020;382:26

${ }^{14}$ Virgolini I, Kurtaran A, Raderer M, et. al. Vasoactive Intestinal Peptide Receptor Scintigraphy. J Nucl Med 1995:36(10):17321739

${ }^{15}$ Mossel EC, Wang J, Jeffers S, et al. SARS-CoV replicates in primary human alveolar type II cell cultures but not in type I-like cells. Virology 2008;372:127-135.

${ }^{16}$ Alessandrini, F., Thakkar, M., Foda, H.D., Said, S.I., Lodi, R., Pakbaz, H., and Schraufnagel, D.E. Vasoactive intestinal peptide enhances lung preservation. Transplantation 1993;56:964-973

${ }^{17}$ Pakbaz H, Berisha H, Sharaf H, Foda HD, Said SI. VIP enhances and nitric oxide synthase inhibitor reduces survival of rat lungs perfused ex vivo. Ann. N. Y. Acad. Sci. 1994;723:426-428

${ }^{18} \mathrm{Li}$, L., Luo, Z.Q., Zhou, et. al. Effect of vasoactive intestinal peptide on pulmonary surfactants phospholipid synthesis in lung explants. Acta Pharmacol. Sin. 2004;25:1652-1658

${ }^{19} \mathrm{Li} \mathrm{L}$, She H, Yue S, et. al. Role of C-Fos gene in vasoactive intestinal peptide promoted synthesis of pulmonary surfactant phospholipids. Regul Pept 2007;140(3):117-124

${ }^{20}$ Li L, Hua S, Yue S, Luo Z, et. al., Vasoactive intestinal polypeptide induces surfactant protein A expression in ATII cells through activation of PKC/c-Fos pathway. Peptides 2010;31(11):2016-2051 
${ }^{21}$ Onoue S, Ohmori Y, Endo K, Yamada S, Kimura R, Yajima T. Vasoactive intestinal peptide and pituitary adenylate cyclaseactivating polypeptide attenuate the cigarette smoke extract-induced apoptotic death of rat alveolar L2 cells. Eur. J. Biochem. 2004;271: 1757-1767.

${ }^{22}$ Mathioudakis AG, Chatzimavridou-Grigoriadou V, Evangelopoulou E, Mathioudakis GA. Vasoactive Intestinal Peptide Inhaled Agonists: Potential Role in Respiratory Therapeutics. Hippokratia 2013;17(1):12-16

23 Jacobs JP, Stammers AH, St Louis J, et al. Extracorporeal membrane oxygenation in the treatment of severe pulmonary and cardiac compromise in COVID-19: experience with 32 patients. ASAIO J 2020; epub ahead of press. 
Figures

\section{Effect of VIP on Blood Oxygenation}

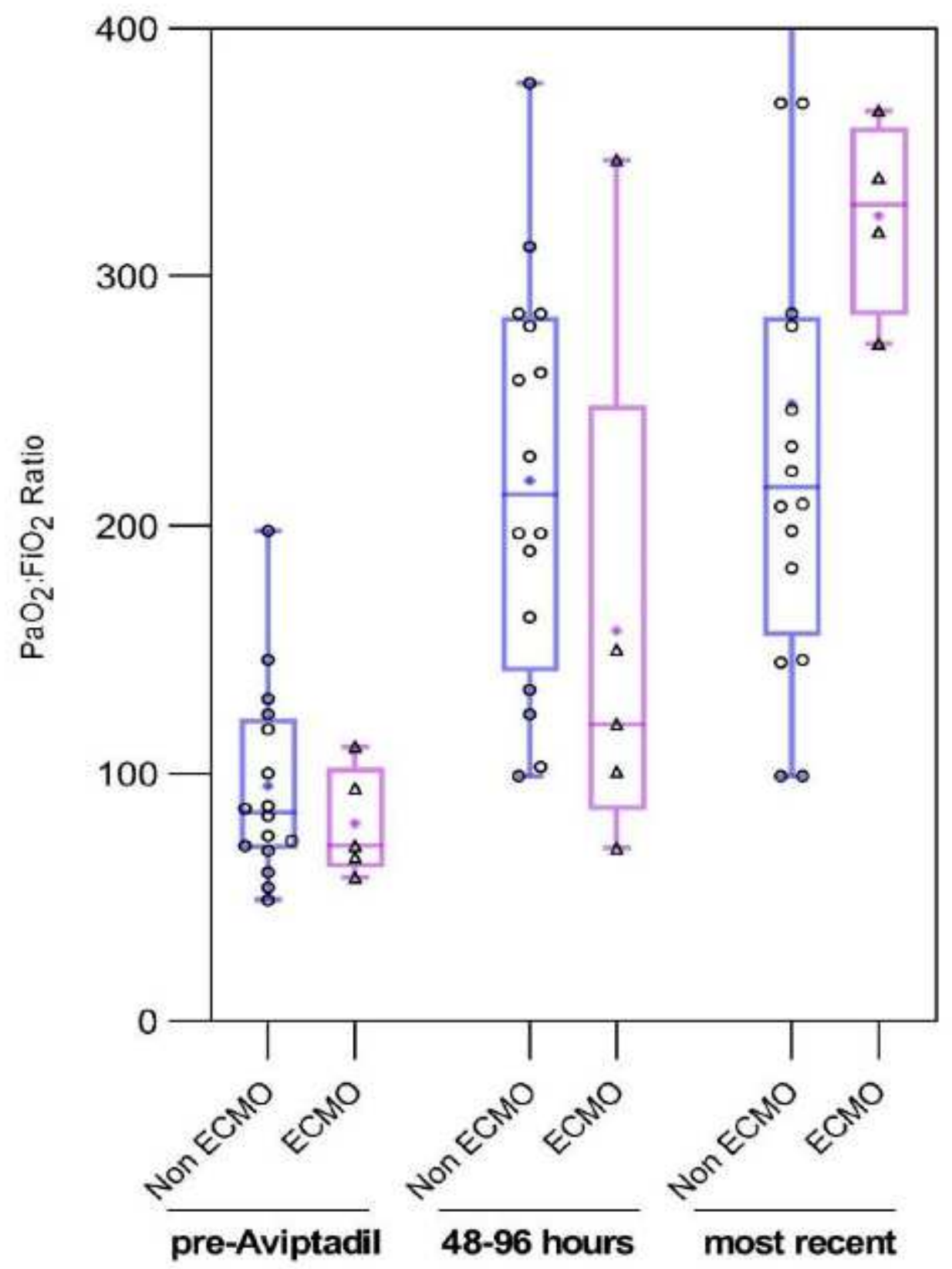

Figure 1

Effect of VIP on blood oxygenation. A 3-fold improvement in PaO2:FiO2 ratio can be seen overall $(\mathrm{P}<.001)$ with 20 of 21 patients demonstrating improved oxygenation. Similar trends are seen in those treated with $(n=5)$ and without ECMO $(n=16)$ 


\begin{tabular}{|l|l|l|}
\hline $\begin{array}{c}\text { Prior to Aviptadil } \\
\text { On ECMO and } \\
\text { Mechanical Ventilation }\end{array}$ & $\begin{array}{l}\text { 48-hrs post treatment } \\
\text { On ECMO and } \\
\text { Mechanical Ventilation }\end{array}$ & $\begin{array}{l}\text { 14 days post treatment } \\
\text { Discharged to home } \\
\text { on Room Air }\end{array}$ \\
\hline & & \\
\hline & & \\
\hline & & \\
\hline
\end{tabular}

Figure 2

Chest x-ray and CT imaging of a patient initially treated while on mechanical ventilation and extracorporeal membrane oxygenation for Critical COVID-19 with respiratory failure (see supplemental online material for radiographic documentation of all patients). 


\section{Decrease in Inflammatory Markers}

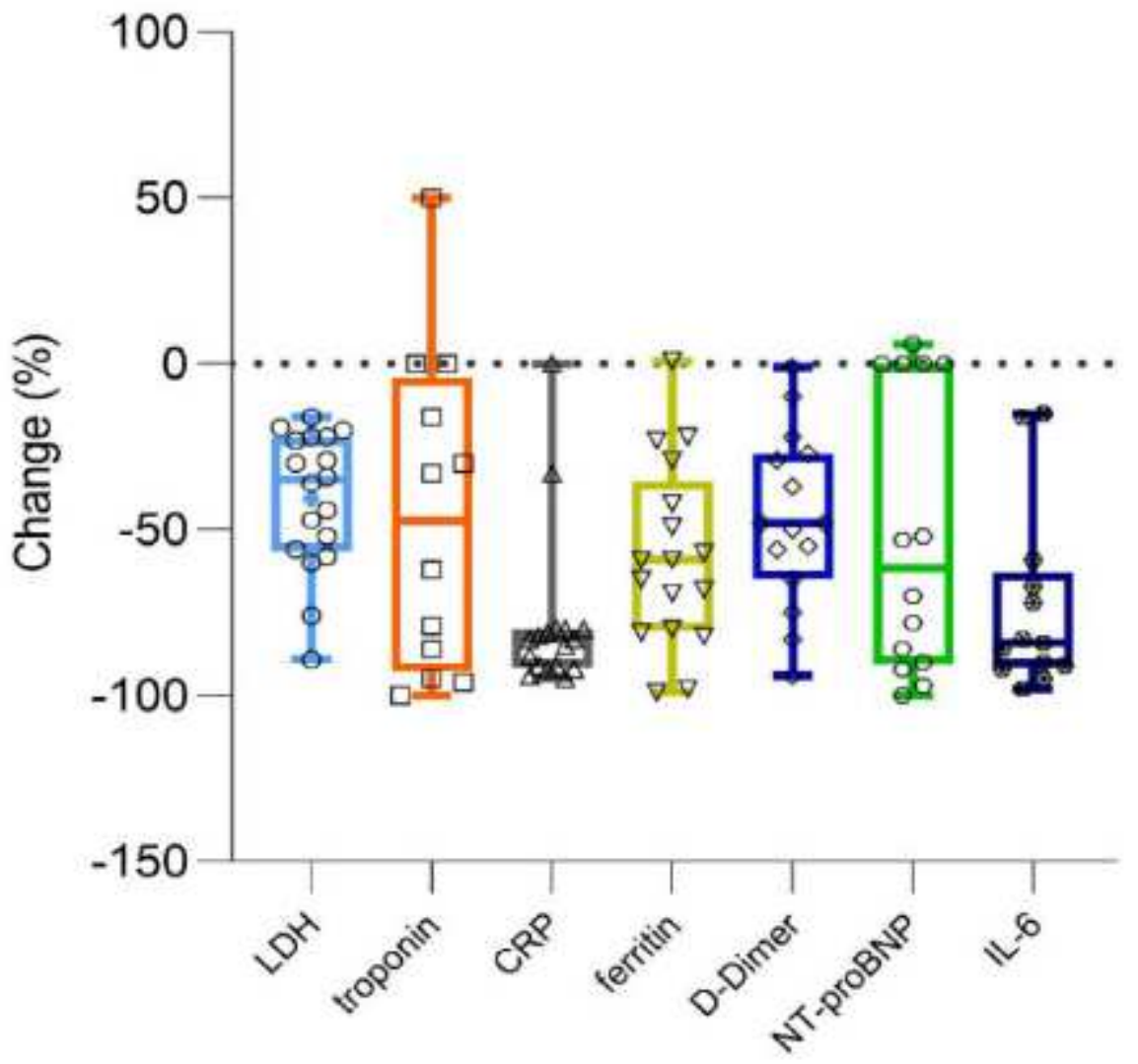

Figure 3

Decrease in inflammatory markers as a percent change from pretreatment value. The decrease is both clinically and statistically significant $(P<.001)$ 


\section{WHO Ordinal Scale}

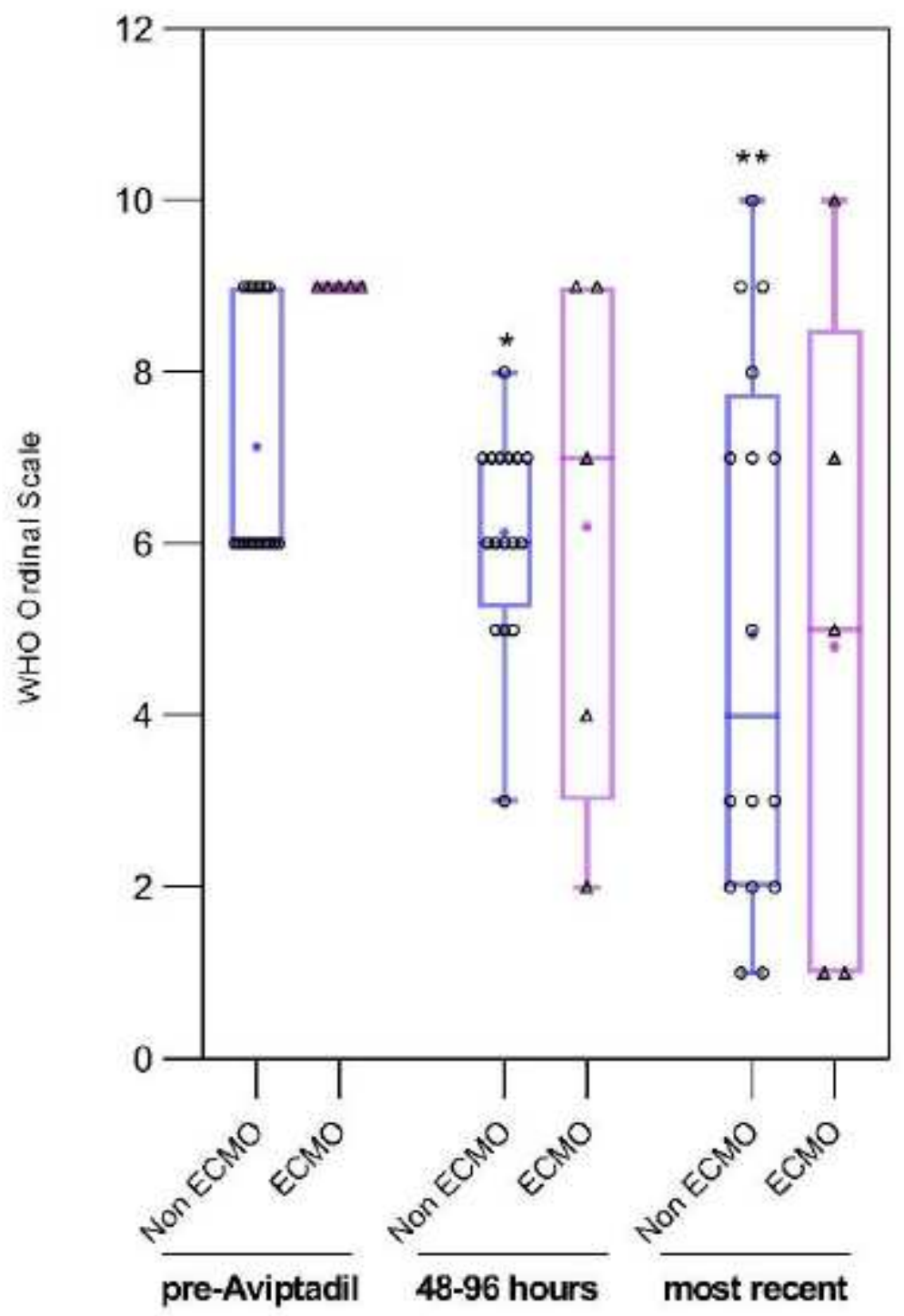

Figure 4

Change in WHO ordinal severity scale in patients treated with ventilation alone $(n=16)$ vs. those treated with ECMO $(n=5)$. Overall, a mean 2.6 point improvement was seen $(P<0.001)$ and is similar in those treated with ventilation alone vs. those treated with ECMO.

\section{Supplementary Files}

This is a list of supplementary files associated with this preprint. Click to download.

- RadiologyandABGpatients121.pdf

- Table1Aug23Rev.pdf 
- YoussefTable2August23.pdf 